\title{
ASSESSMENT OF THE STICKY BONE PREPARATION OF BIOACTIVE BONE GLASS IN GRAFTING CRITICAL-SIZED SURGICAL BONY DEFECTS
}

\author{
Hesham Elsayed El-Hawary* and Mohamed Shawky**
}

\begin{abstract}
Background: Critically sized surgical bony defects after enucleation of cystic bony lesions will not spontaneously heal.

Purpose: This clinical study aimed to assess the osteoinductive potential of bioactive bone glass in the form of sticky bone in critical-sized surgical bony defects.

Patients and methods: the present study is a randomized clinical controlled trial including 24 patients divided into two equal groups. Cystic lesions exceeding $2 \times 2 \mathrm{~cm}$ were enucleated, and the defect was obliterated with bioactive bone glass particles in group 1 and bioactive glass sticky bone in group 2. Bone density was measured in grayscale units from digital panoramic radiographs immediately, at three and six months postoperatively.
\end{abstract}

Results: The healing went uneventful, except for the exfoliation of graft particles through the incision line in groups 1. In group 1, the percentage of decrease in the bone density during the first three months is higher in group 1 than group 2 that was then increased by nearly the same percentage at the six months interval although statisticaly there is no significant difference between the two groups through out the study period.

Conclusion: The bioactive glass prepared as the sticky bone has better intraoperative handling and workability, better soft tissue reaction during the healing period and higher bone density values of the grafted defects than when used solely although it hasn't any radiographic statistical significant results regarding the studied parameters.

KEYWORDS: Cyst, Maxillary cysts, Critical size, bioactive bone glass, sticky bone, bone density, osteoinductive, bone substitute.

* Associate Professor, Oral and Maxillofacial Surgery Department, Faculty of Oral and Dental Medicine, Cairo University, Cairo, Egypt.

** Instructor, Oral and Maxillofacial Surgery Department, Faculty of Oral and Dental Medicine, Cairo University, Cairo, Egypt. 


\section{INTRODUCTION}

Cystic lesions are among the common pathologies known to affect the oral and maxillofacial region. By definition, a cyst is an epithelial lined cavity, filled with fluid or semifluid or gas, as mentioned by $\mathbf{I}$. Kramer in 1974. ${ }^{1}$ According to Partsch ${ }^{2}$, there are two proposed treatment lines; the first one entails a complete excision of the lesion and watertight closure to permit immobile and undisturbed healing. However, large lesions that erode the natural bony barriers and encroach the adjacent vital structures may benefit from another line of treatment called marsupialization, which involves creating a decompression window in the cyst wall that reverse the process of cyst expansion, yielding a relatively smaller lesion that could be removed with minimal or no harm to the surrounding structures. ${ }^{3,4}$

The last treatment modality was recommended for lesions exceeding $2 \mathrm{~cm}$ in diameter because of the increased risk of infection, wound dehiscence due to retraction of the formed blood clot away from the bony walls. Bony defects exceeding 2.5 $\mathrm{cm}$ are critically sized bone defects, as concluded by Emil H. Schemitsch ${ }^{5}$, and tend to have poor natural healing, which led some authors to use gelatin sponge and thrombin to stabilize the blood clot ${ }^{6}$. In the following decades, different grafting materials were investigated for efficiency as filling materials for the cyst cavity following enucleation regarding infection rate reduction, accelerated healing of a better quality bone, and a reduced soft tissue collapse into the bony defect. Autogenous bone is the gold standard. ${ }^{7-9}$ However, it costs an extra donor site morbidity and a longer surgical time for harvesting. The bones harvested from the iliac crest, the mandible, and the tibia were investigated by Holtgrave and Spiessl ${ }^{10}$, Mi Hyun Seo et al. ${ }^{11}$, and Fethi Atil ${ }^{12}$, respectively.

Studies were conducted to determine the most efficient bone substituting substance. Bone substitutes are used to avoid or minimize the common complications associated with harvesting autogenous bone, beta-tricalcium phosphate ( $\beta$-tricalcium phosphate) was mixed with blood and used alone Bicsák et al. ${ }^{13}$ or with the addition of autogenous bone as tried by Horch et al. ${ }^{14}$ Also, nano-hydroxyapatite was used by Gerlach and Niehues. ${ }^{15}$ It has a chemical composition resembling bone and teeth, which allows it to release calcium and phosphate ions that bind to the surrounding bone in addition to being a scaffold that is invaded by bone growth. ${ }^{16}$ Xenograft mixed with red bone marrow was investigated by Horowitz and Bodner ${ }^{15}$, he found that the graft was incorporated incompletely after six months. After one year, it was fully incorporated; however, in some cases, it was more radiodense than the surrounding bone, the same density of the surrounding bone was reached after two years.

Bioactive glass is a resorbable, synthetic bone substituting material with osteoconductive, osteoinductive, and bone binding potentials. ${ }^{17,18} \mathrm{It}$ induces the formation of a silica-rich layer covered by calcium and phosphorous layers on its surface, promoting collagen adhesion, osteoprogenitor cells differentiation ${ }^{19-22}$, and acting as a biodegradable framework for the bone to grow on. ${ }^{19,20}$ Promising results were encountered upon its employment in the management of osteomyelitis and un-united fractures. ${ }^{21}$ It has also been used in maxillary sinus grafting solely in rabbits first ${ }^{22}$, then it was mixed with autogenous bone and used for grafting after maxillary sinus floor elevation in a study performed by $\mathbf{J}$. Menezes et al. in $2018{ }^{18}$, and the results were also promising.

The gold standard bone graft should possess the three cardinal characteristics of autogenous bone, osteogenicity, osteoinductivity, and osteoconductivity. The osteogenic property is present only in autogenous bone, so a growth factors rich substance may be added to compensate for the lack of osteogenic potential. The best examples are the growth factors rich platelet derivatives, such as platelet-rich plasma (PRP), platelet-rich fibrin (PRF), and fibrin-rich gel with concentrated growth factors (CGF) that were used to enhance and speed 
up new bone formation in sinus floor elevation and guided bone regeneration. ${ }^{23-25}$

Hence, this study aimed to investigate the osteogenic capabilities when a bioactive glass is mixed with platelet rich fibrin containing growth factors and used as a sticky bone to fill bony defects following enucleation of maxillary cystic lesions exceeding $2 \times 2 \mathrm{~cm}$ in diameter.

\section{MATERIALS AND METHODS}

This study was conducted in the department of oral and maxillofacial surgery, faculty of dentistry, Cairo University and was compliant with the Declaration of Helsinki (revised in 1975), and with CONSORT (Consolidated Standards of Reporting Trials) principles and the regional ethical review, the board approved the study. All patients were provided an informed consent and agreed to sign. The inclusion criteria for patient selection were; maxillary cystic lesions exceeding 2 × $2 \mathrm{~cm}$ diameter, affecting healthy patients without systemic or local diseases. Exclusion criteria included a history of systemic disease that may complicate bone healing and graft integration, bone metabolic disorders, a history of radiotherapy or chemotherapy.

The recruited patients were interviewed to obtain a thorough medical history, previous dental history, and chief complaint history. During the clinical examination, an aspiration biopsy was done to determine the nature of the lesion being a cyst. A preoperative digital orthopantomogram was requested to exclude other missing underlying diseases (Fig 1). Then an incisional biopsy was done to know the nature of the cystic lesion. According to the biopsy report, patients with lesions that will need bony resection as a definitive treatment were excluded.

Twenty four patients were selected, 14 males and 10 females with ages ranging from 26 to 45 years. They had maxillary cystic lesions exceeding $2 \times 2 \mathrm{~cm}$ and were free from any systemic diseases (table 1).

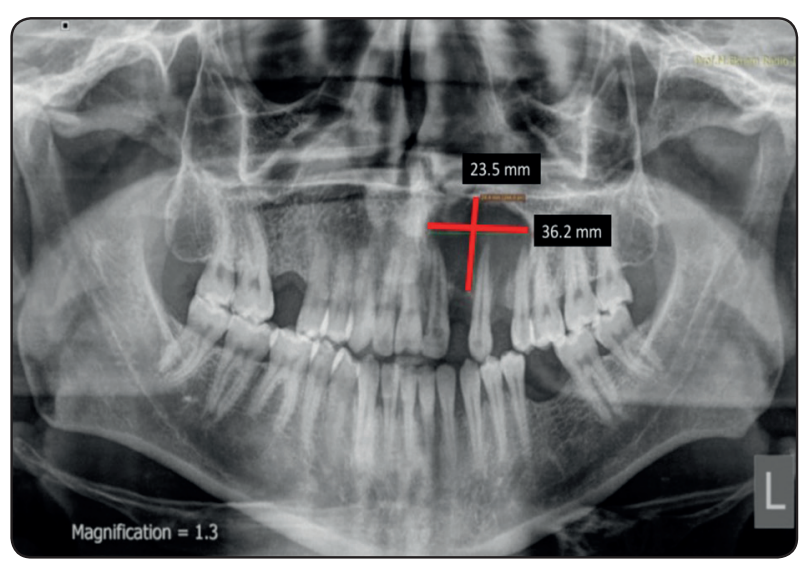

Fig. (1): Preoperative Orthopantomogram with the measurements of the cystic cavity.

TABLE (1) The Demographic Data of the patients.

\begin{tabular}{|l|l|l|l|l|}
\hline & \multicolumn{2}{|c|}{ Group 1 } & \multicolumn{2}{c|}{ Group 2 } \\
\hline Patients & \multicolumn{2}{|c|}{12} & \multicolumn{2}{|c|}{12} \\
\hline & 9 males & 3 females & 5 males & 7 females \\
\hline Age range & \multicolumn{2}{|c|}{$27-45$} & \multicolumn{2}{|c|}{$22-45$} \\
\hline
\end{tabular}

\section{Study design and Randomization}

Patients were randomly divided into two equal groups using a computer permuted block stratified randomization generator (randomization.com).

In group 1, the cyst was enucleated, followed by immediate grafting of the defect using bioactive glass (Noraker, Lyon, France). While in group 2, five males and seven females received a sticky bone prepared from the bioactive glass to and used to obliterated the defect.

\section{Surgical procedure}

Under local anesthesia (ARTINIBSA 40mg Articaine hydrochloride / $\mathrm{ml}+0.01 \mathrm{mg}$ Epinephrine / $\mathrm{ml}$ injectable solution, Inibsa Dental S.L.U., Ctra. Sabadell a, Granollers, Km 14,5 (C-155), 08185 Lliçà de Vall (Barcelona) España), the patients were seated comfortably and given infraorbital nerve 
block and a palatal block anesthesia as recommended to anesthetise the area of the cyst. A sulcular incision was then commenced extending two teeth beyond the area of interest, followed by two oblique incisions on either side of the flap. A fullthickness mucoperiosteal flap was raised, uncovering the buccal bone, which in all of the cases was thin enough to be breached and removed, exposing the cystic lining. The bony opening was then extended enough to provide adequate accessibility before the lesion was enucleated entirely, followed by peripheral ostectomy using a large-sized rose head bur after resecting the root ends of the related teeth or extracting them if needed to ensure total removal of the lining (Fig 2A).

The defect was obliterated using bioactive glass particles in the first group of patients. In the second group, a sticky bone was prepared from the bioactive glass and used as a filling material (Fig $2 \mathrm{~B}, \mathrm{C}$ ).

To prepare the sticky bone, 20 to $40 \mathrm{CC}$ of the patient's venous blood was withdrawn, injected into an even number of non-coated vacutainers (yellow cap), and centrifuged at $2400-2700$ RPM for 2 minutes in a special centrifuge with a rotor turning with alternating and controlled speed (Medifuge, Silfradent Srl, Sofia, Italy). The upper layer containing the autologous fibrin glue (AFG) was withdrawn with a syringe and injected over the bioactive glass, left for $8-10$ minutes to coagulate, forming sticky bone (Fig 2C).

The enucleated lesions' lining was placed in a $10 \%$ formalin solution and sent for histopathological examination. Furthermore, the wound was closed primarily using vicryl 3/0 (Assut, Switzerland). A postoperative antibiotic course of amoxicillin + clavulanic acid $1 \mathrm{~g}$ tab (Augmentin, Galaxo Smith Kline, Cairo, Egypt) was prescribed for one week and Ibuprofen $600 \mathrm{mg}$ tab (Brufen, Kahira pharmaceutical and chemical industries, Cairo, Egypt) twice daily for one week. One shot of dexamethasone $8 \mathrm{mg}$ vial (Sigmatic, Cairo, Egypt) was administered intramuscularly immediately after the surgery together with ketorolac tromethamine $30 \mathrm{mg}$ (Ketolac, Amriya pharm, Alexandria, Egypt).

Postoperative instructions of ice packs application for 15 minutes every 30 minutes during the first 24 hours were given and replaced by warm fomentations with the same rate for the next two days. A soft diet was recommended for the first forty-eight hours. Strict oral hygiene instructions and chlorhexidine mouth wash (Hexitol; ADCO Pharma, Cairo, Egypt) was used three times daily for 15 days starting from the second postoperative day. An immediate digital panoramic radiograph was requested to be done by the same radiologist using the same machine to deduce the baseline bone density in the

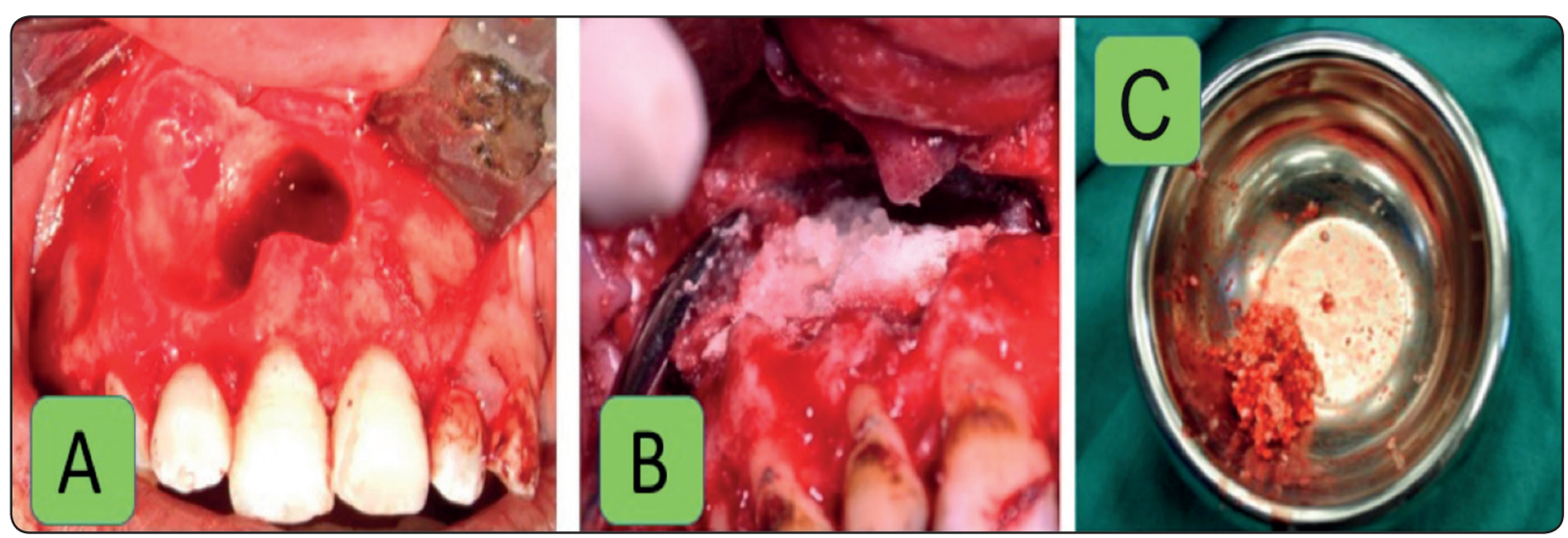

Fig. (2) A: Clinical photograph of the resulted surgical defect after cyst enucleation, B: Clinical photograph of filling the resulted surgical defect with Bioactive bone glass (Group 1), C: Clinical photograph showing the Bioactive glass sticky Bone prior to its use in filling the resulted surgical defect (Group 2). 


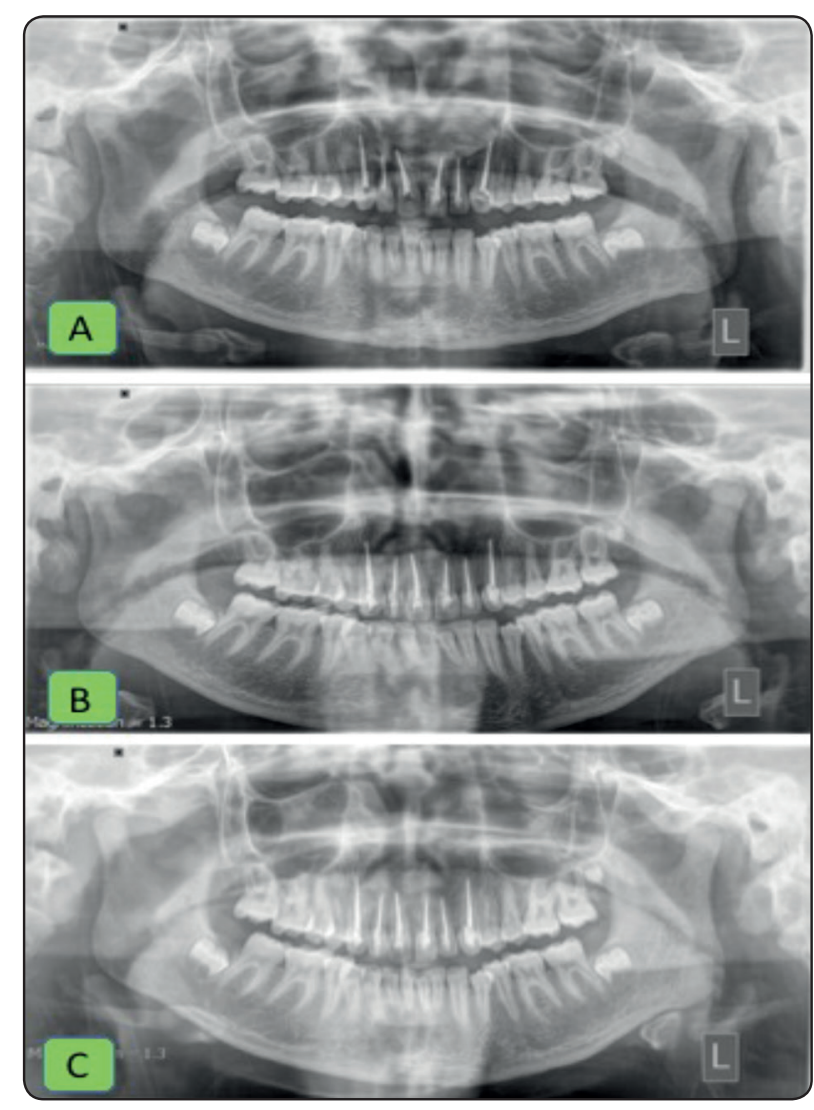

Fig. (3) A: Immediate Postoperative Orthopantomogram, B: 3 months Postoperative Orthopantomogram, C: 6 months postoperative orthopantomograms (Group 2).

grayscale units for the grafted site. It was repeated at 3 and 6 months postoperative (Fig 3A, B, C).

All digital radiographs were taken with the same machine and the same parameters to provide standardization of images. Radiodensitometric analysis was obtained by measuring the relative bone density using the sigma view, Digora software in Gray Scale Units (GSU) (Fig. 04). The obtained measurements were documented and sent for statistical analysis.

The patients were recalled after two days, after one week, at the end of the first month and then at three and six months to monitor the soft tissue healing where the sutures were removed after one week, then at the third and sixth months to evaluate the bony healing.

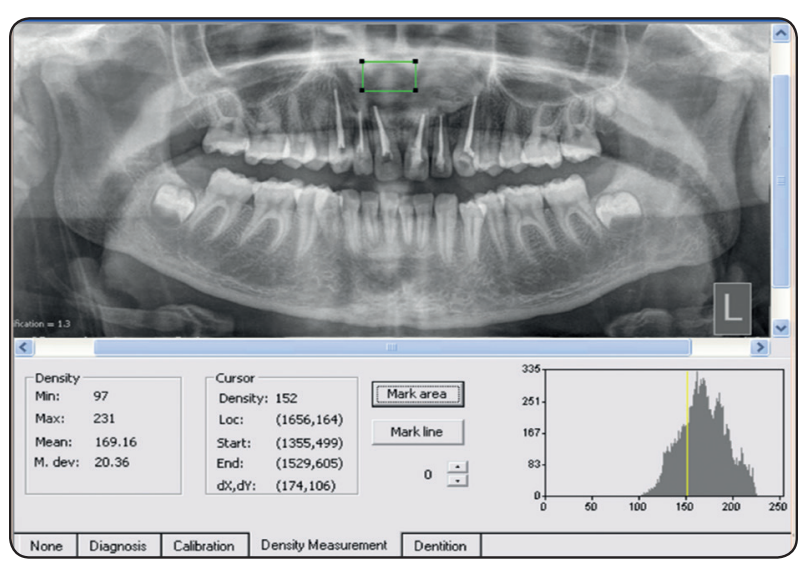

Fig. (4): Photograph showing the screenshot of the bone density measurement from orthopantomogram using Digora software.

\section{Statistical methods}

The statistical analysis implemented data analysis using IBM SPSS. (Statistical Package for Social Sciences, Version 22. SPSS Inc., Chicago, IL). The numerical data were described as means and standard deviations, which examined for normality using the Kolmogrov-Smirnov test. The paired student t-test compared the two variables within the same group. The independent samples t-test compared the variables between the two studied groups. The results were considered statistically significant if the computed p-value counted than 0.05 .

\section{RESULTS}

The current study was conducted on twenty four, 14 males and 10 females patients, ranging from 22 to 45 years old, with a mean age of 33.5. According to the standard techniques, all the cysts were surgically enucleated, and the resulting surgical defects were grafted using the bioactive glass, and bioactive glass sticky bone, according to the study groups. All the patients were included for statistical analysis. Data were reported as mean \pm standard deviation.

\section{Clinical results}

Intraoperatively, the surgical elevation of the buccal flaps went smooth in all of the cases. The 
cysts were completely enucleated with surgical defect obliteration utilizing the examined materials with adequate unstretched complete soft tissue coverage for the bony defects.

The healing went uneventful through all the cases. All the patients complained of postoperative edema and swelling on the surgical site that resolved at the end of the first postoperative week. The patients suffered from pain that was controlled by the prescribed NSAID drug.

At the 48 hours follow up, Two patients in group 1 reported a feeling of escape of the grafting material into the oral cavity; checking the flaps revealed the escape of some graft particles from the gingival incisions that were related to extracted teeth during enucleation, the patients were instructed to follow the prescribed oral hygiene protocol strictly. However, the surgically reconstructed defects did not show postoperative infection nor wound dehiscence or graft rejection throughout the healing phase. After resolving the postsurgical phase's signs, none of the patients exhibited any complaint during the whole study interval.

\section{Radiodenisty results}

For Group 1, the mean value of the bone density measured immediately postoperatively was $137.92 \pm 35.53$ GSU. By the end of the third month, it was reduced to $106.55 \pm 40.67$ GSU. At six months postoperatively, it reached $122.65 \pm 33.35$ GSU. The bone density decreased by $17.6 \%$ at three months' interval then increased by $14 \%$ by the end of the study, with a total decrease in bone density by $5.3 \%$. For Group 2, the mean value of the bone density measured immediately postoperatively was $131.78 \pm 21.27 \mathrm{GSU}$. By the end of the third month, it was reduced to $126.42 \pm 28.22$ GSU. At six months postoperatively, it reached $138.05 \pm 14.77$ GSU. The bone density decreased by $4.5 \%$ at three months, then increased by $8.7 \%$ at the end of the study, with a total increase in bone density by $4.5 \%$. (Fig 5).
TABLE (2) Showing the t-test results and the p-value comparing the three groups.

\begin{tabular}{|c|c|c|}
\hline T-Test & P-Value & Significance \\
\hline $\begin{array}{c}\text { Between G1-G2 } \\
\text { immediate postop record }\end{array}$ & 0.846170198 & Not Sig \\
\hline $\begin{array}{c}\text { Between G1-G2 } \\
\text { 3 months' record }\end{array}$ & 0.179986149 & Not Sig \\
\hline $\begin{array}{c}\text { Between G1-G2 } \\
\text { 6 months' record }\end{array}$ & 0.16399939 & Not Sig \\
\hline
\end{tabular}

Comparing all groups along the whole study period, there was a nonsignificant statistical difference in the grayscale measurement.

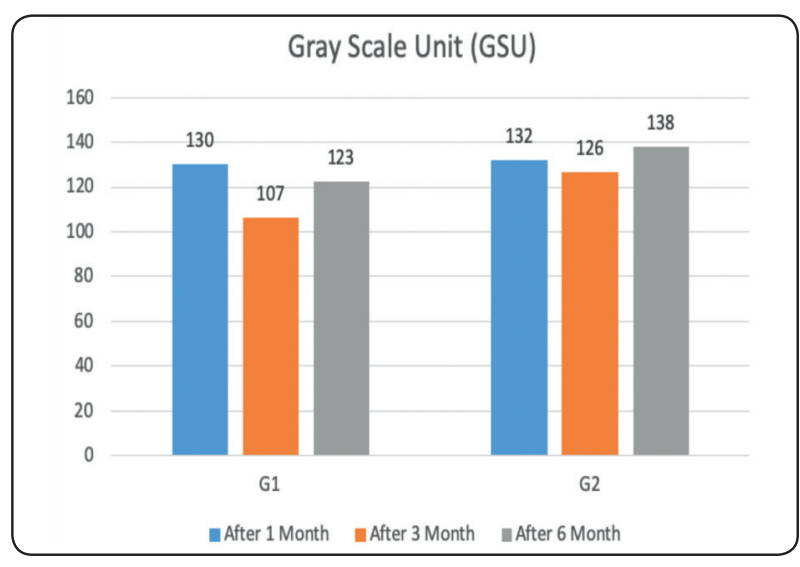

Fig. (5): Diagram Showing the mean bone density for all groups along the entire study period.

\section{DISCUSSION}

Bony defects that reach the critical size are not going to heal spontaneously. That is why they are considered clinically problematic. In large defect sizes, the formed blood clot will disintegrate and retract or be superimposed by infection. Moreover, a contour defect arises from the collapse of the surrounding soft tissue into the cavity. Grafting of critically sized surgical bony defects may eliminate or reduce all these potential complications. ${ }^{5,26}$ Since alloplasts demonstrated effectiveness in treating postoperative bone defects as suggested by many 
authors ${ }^{5,25-29}$, the present study aimed to investigate whether optimum osseous healing could be achieved with autogenous bone substitutes.

Among the variety of available substitutes nowadays, bioactive glass has been widely investigated for its biocompatibility, bone binding properties, and acting as an osteoconductive scaffold. Besides, it possesses an osteoinductive potential inducing and speeding up bone formation in the area of interest. It was praised by Fetner et al. ${ }^{30}$ for its workability, convenient handling, and hemostatic properties when he used it in periodontal defects and called it PerioGlas. Schepers ${ }^{31}$ in 1991, Furusawa 32 in 1998 , Froum ${ }^{32}$ in 2002, and many other authors $16,19,28$ discussed the advantages of using bioactive glass in surgical defects and recommended its use.

In the present study, the defects were all located in the maxilla to standardize the results. The defects' size was regarded as critical, being more than $2 \times 2 \mathrm{~cm}$ in all the cases. Hence it was indicated for grafting. 5,26,27 All the recruited patients were medically free, which eliminated any underlying systemic condition that may affect healing. As recommended in the literature, aspiration biopsy was done before any intervention to determine the nature of the contents. ${ }^{33}$

The decision to enucleate the cystic lesions was a recommended radical means of treatment to allow the complete histological examination of the full lining and eliminate the need for a close postoperative follow-up in the marsupialization technique. This was preceded by a root canal treatment of the related teeth as recommended in the literature. ${ }^{33,34}$

The application of the bioactive glass sticky bone form in group 2 is easy and convenient than the bioactive glass alone; this is due to the sticky effect of the grafted material that allow to insert it in a bulk form rather than particulate form. Thus the sticky bone form is convenient during its application due to the superior workability. The healing went uneventful through all the cases, except for the exfoliation of the graft particles (popcorn effect) that was reported in the group 1 but not in group 2, which comes in favor of the bioactive glass sticky consistency in that study group. All that in addition to the accelerated bone and soft tissue healing are advantages that come in accordance to Sohn et al. in $2015 .{ }^{35}$

In both groups, bone density changes were measured using direct digital radiography (DDR) at the specific follow-up appointments, immediately, three then six months postoperatively. DDR facilitated the detection of both the qualitative and quantitative changes of bone density. Barbet and Messer ${ }^{36}$ stated that it is more accurate and sensitive than conventional radiography, and on the other hand, it offers less radiation exposure than cone-beam computed tomography. ${ }^{37}$ Radiodensitometric analysis was obtained by measurement of the relative bone density using the sigma view, Digora software.

The documented data were tabulated as mean and standard deviation and sent for statistical analysis. The computerized image analysis system was an appropriate tool for detecting changes in bone density as it provides numeric values for the progression of the healing process. This goes with the results stated by Delano et al. in 2001. ${ }^{38}$

A postoperative orthopantomogram was requested immediately postoperatively, after three months and after six months. The bone density measurements revealed a nonsignificant reduction in bone density after three months. Although it is nonsignificant, it can be justified due to the phagocytosis process in the graft core, osteoid formation, and the released silicon rich layer that is readily absorbed and excreted. However, in the six months investigation, the density increased again in both groups, which is explained by the recruitment of osteoblasts, mesenchymal cells and the additional crystallization of the layed down bone matrix thus increasing the radiodensity. This is facilitated by the precipitated layer of calcium and ohosphate over the silicon rich layer. ${ }^{39}$ 
The statistical results are insignificant along the study period comparing both groups, but regarding the percentage of bone density change; group 2 showed a less percentage in change in the three months interval compared to group 1 but both of them showed nearly the same increase in percentage of bone density change. This might be due to the immediate and early effect of the growth factors and interlukins in the sticky bone which improves its radiographic properties in group 2 than in group 1 , thus the sticky bone preparation has a resultant higher bone density regarding the three months bone density.

\section{CONCLUSION}

The bioactive glass prepared as sticky bone has better intraoperative handling and workability, better soft tissue reaction during the healing period, and higher bone density values of the grafted defects than when used solely although it hasn't any radiographic statistical significant results regarding the studied parameters.

\section{Recommendations}

Bioactive glass prepared as sticky bone is recommended for grafting critically sized surgical bony defects over its use in a particulate form due to its better clinical handling, biocompatibility, soft tissue reaction, and the higher density of the formed bone specialy in the early healing phase.

Further studies are recommended for a histomorphometric analysis of the grafted area to better investigate grafted site histology in different timelines and the bone area percent.

\section{Conflict-of-interest notification}

The authors declare that they have no conflict of interest with the contents of this article.

\section{Funding sources/sponsors}

Self-funded.

\section{REFERENCES}

1. KramerIR.Changing ViewsonOralDisease.ProcRSocMed. 1974;67(4):271-276. doi:10.1177/003591577406700414

2. C P. No Zur Behandlung der Kieferzysten. Dtsc Mschr Zahnheilkunde. Dtsch Mschr Zahnheilkd. 1910;28:252.

3. Lim HK, Kim JW, Lee UL, Kim JW, Lee H. Risk Factor Analysis of Graft Failure With Concomitant Cyst Enucleation of the Jaw Bone: A Retrospective Multicenter Study. J Oral Maxillofac Surg. 2017;75(8):1668-1678. doi:10.1016/j.joms.2017.02.003

4. Lizio G, Sterrantino AF, Ragazzini S, Marchetti C. Volume reduction of cystic lesions after surgical decompression: A computerised three-dimensional computed tomographic evaluation. Clin Oral Investig. 2013;17(7):1701-1708. doi:10.1007/s00784-012-0869-z

5. Roddy E, DeBaun MR, Daoud-Gray A, Yang YP, Gardner MJ. Treatment of critical-sized bone defects: clinical and tissue engineering perspectives. Eur J Orthop Surg Traumatol. 2018;28(3):351-362. doi:10.1007/s00590-017-2063-0

6. Dickmeiss B, Hauenstein H, Schettler D. [Filling of bone defects with human fibrin concentrate in large jaw cysts]. Dtsch Zahnarztl Z. 1985;40(6):653-656.

7. Khoury F, Hanser T. Mandibular Bone Block Harvesting from the Retromolar Region: A 10-Year Prospective Clinical Study. Int $\mathrm{J}$ Oral Maxillofac Implants. 2015;30(3):688-697. doi:10.11607/jomi.4117

8. Bastos AS, Spin-Neto R, Conte Neto N, et al. Calvarial autogenous bone graft for maxillary ridge and sinus reconstruction for rehabilitation with dental implants. J Oral Implantol. 2012:120409091007002. doi:10.1563/ aaid-joi-d-11-00090.1

9. Elhadidi M, Aldahouk A, Shawky M, Elbehairy MS, Atef M, El-Gengehi M. Computer-guided calvarial mono-cortical bone blocks harvest: A novel approach for three-dimensional alveolar reconstruction of atrophic maxilla. Clin Implant Dent Relat Res. 2019;21(1):85-93. doi:10.1111/cid.12714

10. Holtgrave E, Rakosi T, Spiessl B. New Concepts in Maxillofacial Bone Surgery. Vol 53. (Spiessl B, ed.). Berlin, Heidelberg: Springer Berlin Heidelberg; 1976. doi:10.1007/978-3-642-66484-7

11. Seo MH, Eo MY, Cho YJ, Kim SM, Lee SK. Autogenous Partial Bone Chip Grafting on the Exposed Inferior Alveolar Nerve after Cystic Enucleation. J Craniofac Surg. 2018;29(2):486-490. doi:10.1097/SCS.0000000000004077 
12. Atil F, Kocyigit ID, Suer BT, et al. Clinical Evaluation of the Use of Tibial Bone Grafting in Dentoalveolar Reconstructive Surgery. Med Princ Pract. 2016;25(1):7278. doi:10.1159/000440998

13. Bicsák Á, Bogdán S, Barabás J, Szabó G. P.082 Mediumterm study on filling large bone defects with betatricalcium-phosphate (Cerasorb®). J Cranio-Maxillofacial Surg. 2006;34:152. doi:10.1016/S1010-5182(06)60589-1

14. Horch HH, Sader R, Pautke C, Neff A, Deppe H, Kolk A. Synthetic, pure-phase beta-tricalcium phosphate ceramic granules $\left(\right.$ Cerasorb $\left.{ }^{\circledR}\right)$ for bone regeneration in the reconstructive surgery of the jaws. Int J Oral Maxillofac Surg. 2006;35(8):708-713. doi:10.1016/j.ijom.2006.03.017

15. Gerlach KL, Niehues D. Die Behndlung der Kieferzysten mit einem neuartigen nanopartikulären Hydroxylapatit. Mund - Kiefer - und Gesichtschirurgie. 2007;11(3):131137. doi:10.1007/s10006-007-0064-6

16. Kim BK, Kim SG, Kim SY, Lim SC, Kim YK. A comparison of bone generation capability in rabbits using tooth ash and plaster of Paris with platelet-rich plasma or fibrin sealant. Oral Surgery, Oral Med Oral Pathol Oral Radiol Endodontology. 2010;110(3):e8-e14. doi:10.1016/j. tripleo.2010.03.031

17. Montazerian M, Dutra Zanotto E. History and trends of bioactive glass-ceramics. J Biomed Mater Res - Part A. 2016;104(5):1231-1249. doi:10.1002/jbm.a.35639

18. Menezes Jd, Pereira R Dos S, Bonardi Jp, Griza Gl, Okamoto R, Hochuli-Vieira E. Bioactive glass added to autogenous bone graft in maxillary sinus augmentation: a prospective histomorphometric, immunohistochemical, and bone graft resorption assessment. J Appl Oral Sci. 2018;26:e20170296. doi:10.1590/1678-7757-2017-0296

19. Jones JR. Review of bioactive glass: From Hench to hybrids. Acta Biomater. 2013;9(1):4457-4486. doi:10.1016/j.actbio.2012.08.023

20. Liu X, Rahaman MN, Fu Q. Bone regeneration in strong porous bioactive glass (13-93) scaffolds with an oriented microstructure implanted in rat calvarial defects. Acta Biomater. 2013;9(1):4889-4898. doi:10.1016/j. actbio.2012.08.029

21. Al Malat T, Glombitza M, Dahmen J,Hax PM, Steinhausen E. The use of bioactive glass S53P4 as bone graft substitute in the treatment of chronic osteomyelitis and infected nonunions - A retrospective study of 50 patients. Z Orthop Unfall. 2018;156(2):152-159. doi:10.1055/s-0043-124377
22. Vivan RR, Mecca CE, Biguetti CC, et al. Experimental maxillary sinus augmentation using a highly bioactive glass ceramic. J Mater Sci Mater Med. 2016;27(2):1-10. doi:10.1007/s10856-015-5652-7

23. Zhang N, Wu Y-P, Qian S-J, Teng C, Chen S, Li H. Research Progress in the Mechanism of Effect of PRP in Bone Deficiency Healing. Sci World J. 2013;2013:1-7. doi:10.1155/2013/134582

24. Öncü E, Bayram B, Kantarcı A, Gülsever S, Alaaddinoğlu EE. Positive effect of platelet rich fibrin on osseointegration. Med Oral Patol Oral Cir Bucal. 2016;21(5):e601e607. doi:10.4317/medoral.21026

25. Rodriguez IA, Growney Kalaf EA, Bowlin GL, Sell SA. Platelet-Rich Plasma in Bone Regeneration: Engineering the Delivery for Improved Clinical Efficacy. Biomed Res Int. 2014;2014:1-15. doi:10.1155/2014/392398

26. Schemitsch EH. Size Matters: Defining Critical in Bone Defect Size! J Orthop Trauma. 2017;31(10):S20-S22. doi:10.1097/BOT.0000000000000978

27. SCHMITZ JP, HOLLINGER JO. The Critical Size Defect as an Experimental Model for Craniomandibulofacial Nonunions. Clin Orthop Relat Res. 1986;NA;(205):299???308. doi:10.1097/00003086-198604000-00036

28. Kim SY, Kim SG, Lim SC, Bae CS. Effects on bone formation in ovariectomized rats after implantation of tooth ash and plaster of Paris mixture. J Oral Maxillofac Surg. 2004;62(7):852-857. doi:10.1016/j.joms.2003.12.023

29. Buchbender M, Neukam FW, Lutz R, Schmitt CM. Treatment of enucleated odontogenic jaw cysts: a systematic review. Oral Surg Oral Med Oral Pathol Oral Radiol. 2018;125(5):399-406. doi:10.1016/j.oooo.2017.12.010

30. Fetner AE, Hartigan MS, Low SB. Periodontal repair using PerioGlas in nonhuman primates: clinical and histologic observations. Compendium. 1994;15(7):932,935-938; quiz 939.

31. SCHEPERS E, CLERCQ M DE, DUCHEYNE P, KEMPENEERS R. Bioactive glass particulate material as a filler for bone lesions. J Oral Rehabil. 2008;18(5):439-452. doi:10.1111/j.1365-2842.1991.tb01689.x

32. Furusawa T, Mizunuma K, Yamashita S, Takahashi T. Investigation of early bone formation using resorbable bioactive glass in the rat mandible. Int J Oral Maxillofac Implants. 1998;13(5):672-676.

33. Fonseca RJ. Oral and maxillofacial surgery. 2018. https:// www.clinicalkey.com/dura/browse/bookChapter/3s2.0-C20141001032. 
34. Pechalova PF, Bakardjiev AG, Beltcheva AB. Jaw cysts at children and adolescence: A single-center retrospective study of 152 cases in southern Bulgaria. Med Oral Patol Oral Cir Bucal. 2011;16(6):767-771. doi:10.4317/medoral.16849

35. Dong-Seok Sohn BH, Jin Kim, W. Eric Park CCP. Utilization of Autologous Concentrated Growth Factors (CGF) Enriched Bone Graft Matrix (Sticky Bone) and CGF-Enriched Fibrin Membrane in Implant Dentistry. J Implant Adv Clin Dent. 2015;7(10):17-29. http://jiacd. com/wp-content/files_mf/1451940224JIACDDec15.pdf.

36. Barbat J, Messer HH. Detectability of artificial periapical lesions using direct digital and conventional radiography. J Endod. 1998;24(12):837-842. doi:10.1016/S00992399(98)80014-9
37. James Mistak E, Loushine RJ, Primack PD, West LA, Runyan DA. Interpretation of periapical lesions comparing conventional, direct digital, and telephonically transmitted radiographic images. J Endod. 1998;24(4):262-264. doi:10.1016/s0099-2399(98)80110-6

38. Delano EO, Ludlow JB, Ørstavik D, Tyndall D, Trope M. Comparison between PAI and quantitative digital radiographic assessment of apical healing after endodontic treatment. Oral Surgery, Oral Med Oral Pathol Oral Radiol Endodontology. 2001;92(1):108-115. doi:10.1067/ moe.2001.115466

39. Venkataraman N, Bansal S, Bansal P, Narayan S. Dynamics of bone graft healing around implants. J Int Clin Dent Res Organ. 2015;7(3):40. doi:10.4103/2231-0754.172930 